\title{
The Integrative English Major: Cultivating Growth, Transformation, and Possibility
}

\section{Leeann Hunter}

The author is assistant director of undergraduate studies and clinical assistant professor of English and digital technology and culture at Washington State University, Pullman. A version of the essay was presented at the 2017 MLA Annual Convention in Philadelphia.
STUDENTS in the English major often ask what kind of career they can pursue with their degree. The truth is, our majors won't step into one single career or one single life after graduation but rather into many careers and many lives. What our students need to learn most about their careers is a message that many of us try to deliver in our writing instruction: that with every word we type, the potential for a new idea is born. Every paragraph we compose leads to a sharper focus, increased sense of purpose, and the capacity for new changes. Every draft provides an opportunity to look backward, move forward, and open new doors. Just as there is no single text, there is no single career and no single life. ${ }^{1}$ In the twenty-first century, we weave in and out of careers, rewriting our identities and cycling through revisions of our lives, our societies, and our technologies. Our careers are as much about invention, reflection, and revision as the writing process itself is. Through integrative learning methods, we can teach students how to transfer these skills from the classroom to their personal and professional lives. The Association of American Colleges and Universities defines integrative learning as "an understanding and a disposition that a student builds across the curriculum and co-curriculum, from making simple connections among ideas and experiences to synthesizing and transferring learning to new, complex situations within and beyond the campus" ("Integrative and Applied Learning"). Integrative learning refers not only to the synthesizing of various disciplines in a single course of study but also to connecting new knowledge to personal experiences and to experimenting in various literacies and modalities that facilitate the transfer of knowledge from academic contexts to public and professional contexts.

My career has been one of continual transformation and reflective integrative practices as I have adapted to new rhetorical situations, contexts, and audiences. ${ }^{2}$ From creative writing to digital editing and publishing, from literary studies to the digital humanities, and from $\mathrm{PhD}$ graduate to non-tenure-track faculty member, I have reinvented my professional identity while navigating personal obstacles and objectives. Yet these changes appear small when I step back and consider my professional identity on a larger scale. My most extraordinary transformation was from a fourth-grade student who struggled with reading, writing, speaking, and listening to my current position as an English professor. As a child of deaf parents, the abstract words and symbols on the page were no match for my nonverbal, visual, and spatial experience of the world in American Sign Language. ${ }^{3}$ Mo re significant, at the age of four, I suffered my first traumatic assault, in what would be a lifetime of repeat traumas, executed against my body, my mind, and my sense of purpose and personal value in the world. As I reflect on these stories to better understand how I survived 
The Integrative

English Major:

Cultivating Growth,

Transformation, and

Possibility

Leeann Hunter these obstacles, one lesson I learn is that I didn't do it alone. I was supported by a friend who took me by the hand to show me I belonged and by an English teacher who told me time and again that I had a unique voice. These lessons inform the decisions I make every day as I aspire to cultivate an academic culture that meaningfully mentors students on navigating difficulties and crafting possible futures.

Our student populations are more complex and diverse than ever before, and if English departments seek to serve these students, they will need to commit to transformative learning experiences that meet students where they are and invest in their possibilities for growth. Many of our students have, like me, quietly suffered oppressive forces that reach out to silence them and to tell them they are not valuable. When English teachers operate under deficit models, focusing on how students fail to conform to writing conventions rather than focusing on how they create meaning through writing, we are telling students that they, and their stories, do not belong in an English department. In this era of decreased state funding, in which institutions of higher education count students in terms of dollar signs, it is more important than ever that our faculty and our disciplines learn to adapt proactively and ethically on the side of our students. If our discipline can open itself up to an integrative and multimodal approach to writing that considers students as complex human beings moving through time and space, we will make a more ambitious investment in our students' lives and their futures.

\section{The Passport Program}

While meeting curricular requirements may result in a degree, a degree does not produce a job, ${ }^{4}$ and a job does not necessarily produce happiness. People across all disciplines report feeling unengaged at work. Yet there are known high-impact practices that can lead to feelings of fulfillment. The 2014 Gallup-Purdue Index Report observes that students who participated in internships, undergraduate research, and leadership activities were three times more likely to feel engaged at work (Great Jobs 9). In addition to high-impact practices, the report also addresses mentoring, noting that if college graduates "had a professor who cared about them as a person, one who made them excited about learning, and had a mentor who encouraged them to pursue their dreams, the graduate's odds of being engaged at work more than doubled" (7). The problem is that very few students report access to such transformative mentoring and professional development activities. ${ }^{5}$

To meaningfully involve students in high-impact practices that can lead to longterm adaptability and well-being in their careers, I launched a new program at Washington State University, Pullman. ${ }^{6}$ The Passport Program—a humanities-oriented approach to academic success, leadership, and professional development-mobilizes students to explore pathways beyond the classroom and beyond the university. The Passport Program provides a transformational learning experience, focused on building a sense of purpose at WSU and beyond, and it is currently offered in three parts: Passport Academic, an exploratory one-credit seminar for lower-division students and transfer students that introduces students to integrative methods in academic research; Passport Professional, a capstone, one-credit seminar for upper-division 
The Integrative

English Major:

Cultivating Growth,

Transformation, and

Possibility

Leeann Hunter students that helps students craft and articulate their professional identities; and Passport Mentoring, ongoing access to academic and professional support.

We move between life writing and reflection, building relationships in the community, and practicing the multifaceted features of studies in English, solidifying our viewpoint as essentially narrative, creative, and rhetorical. We analyze, we make, we assess, and we revise. Activities in the Passport Program form action-oriented, relationship-building, and confidence-building mind-sets:

Action-oriented activities: students produce a range of materials, including personal statements, aspirational biographies, and passion pitches. They attend campus activities and events, develop team-oriented leadership projects, and create a blueprint of semester goals, which include specific, personally challenging, measurable activities.

Relationship-oriented activities: students build relationships with their peers through small-group activities and one-on-one peer mentoring. They build relationships with their faculty members through one-on-one meetings and interviews, and small-group activities in the workshop setting. They build relationships with their community through service-learning and sociallearning assignments, internships, and other extracurricular opportunities.

Creative-thinking activities: students identify their current strengths and values, making creative connections between their course work and their professional aspirations. They identify areas for adaptability and multiple literacies; we build a growth mind-set in which students are encouraged to apply themselves to challenging opportunities, creating change for themselves and for others.

While the program is committed to student success, resilience, persistence, and longterm professional well-being, I want to share two pieces that illustrate most powerfully these integrative approaches to academic and professional development in the English major.

\section{Passport Academic: Finding Your Why}

At the heart of the Passport Program is an integrative life-writing method dedicated to finding your why, where students participate in creative writing, storytelling, and close-reading activities that draw on memory, sensory experiences, and affect to deliver a personal statement about how they see the world and hope to affect it. ${ }^{7}$ The method draws on various concepts, from Virginia Woolf's moments of being to Simon Sinek's popular golden circle in his book Start with Why, and my practices are supported by current research in affective neuroscience and narrative psychology. ${ }^{8}$

Modeling the process by sharing simple, yet foundational, memories of my own, I prompt students to identify six memories to record into a worksheet with six circlesthe circles symbolize the moments of being caught amid the infinite pool of nonbeing that flows between the circles. ${ }^{9}$ The moments we isolate and recover become the basis for new texts. This step draws important attention to writing as a selection process. Looking back on the entire stream of their personal history, students select 
The Integrative

English Major:

Cultivating Growth,

Transformation, and

Possibility

Leeann Hunter just a few minutes to analyze. We treat their memories as complex texts that can be written and rewritten. We delve into the texture of these memories, paying attention to the sensory details, the people present, the mood, and the setting. This creative life writing activity produces written artifacts that can be examined and unpackaged.

From these written artifacts, we enact our skills in literary studies as we search for meaningful patterns within and across the texts. What common beliefs or values seem to surface? What contexts are important to the narratives? The goal is to teach students how to identify patterns in their stories and how to implement these patterns in designing self-directed projects. The practical skills learned in this exercise are selection, production, analysis, and application. The deepest learning arises from reframing students' narratives through empowering lenses and developing personal insight into the emotions that inform their academic practices and values.

The finding-your-why method is integrative not only because it incorporates elements from a variety of disciplines within English but also because it incorporates the whole student experience-acknowledging how past experiences imprint themselves on students' mind-sets and can contribute to their growth and development.

\section{Passport Professional: Communicating Your Why}

Recent studies in business psychology show that success often follows those who most deeply believe in their message because it comes across through mostly unconscious nonverbal cues in the voice, facial expressions, and overall presence. ${ }^{10}$ Thus, as students move through the program, we focus on creating coherence between their personal values and the work they aspire to pursue. In the Passport Professional seminar, we work on storytelling, aspirational biographies, and leadership projects to promote students' competence in articulating their professional identity. The seminar facilitates the development of a professional ethos rooted in continuous growth, adaptation, and possibility, teaching techniques that enable students to showcase their professional identity, experience, and potential, including meaning-making practices in interpersonal communication.

One way we help students develop competence in professional communication is through performing arts activities. During fall 2016, the WSU performing arts professor Mary Trotter and I developed four workshops to help students confront many of their performance fears and develop awareness of their nonverbal communication patterns. Activities include presentations, voice and speech exercises, body language and movement, and interviews. The students begin the semester with a bag presentation, an activity that asks students to deliver a speech based on four objects: one object to symbolize a story from their past, one to represent the present, one to represent the future, and a special bag that serves as a container and frame for the objects and stories. Mary introduced this assignment to the Passport Program as a way to bring our written storytelling activities into oral performance, and the students readily step into their roles, accompanied by their props and their stories, giving us a glimpse of their biggest dreams. Over the course of the semester, we regularly share stories each week to build community and practice oral communication skills_-and students learn how these stories can serve them in a variety of settings, 
The Integrative

English Major:

Cultivating Growth,

Transformation, and

Possibility

Leeann Hunter including networking, interviewing, and project pitching. Students end the semester with a passion pitch on a project they have designed over the course of the semester, so they can experience what it feels like to light up while they're talking about the work they love doing. Our goals include teaching students to engage with their most authentic self in interpersonal communication, to draw on personal sources of motivation through storytelling, and to creatively intersect that motivation with various career paths and activities.

Students develop strong integrative and multimodal communication skills over the course of the program. Their portfolio of work includes technical and professional writing, digital production, oral presentations, and creative life writing. These approaches to composing their lives and careers also entail our mentoring students through personal challenges, such as family hardships, financial pressures, psychological barriers, and institutional obstacles, because we recognize that academic work and professional careers do not exist in perfect silos separate from our personal lives.

\section{Reflections and Provocations}

To learn how to write, students need to know why they're writing and what they're writing toward. Real writing begins when we discover that we have something to communicate and that we're willing to labor over multiple drafts until we arrive as close as possible to coherence between message and communication. ${ }^{11}$

I was lucky to realize that message as a high school student over twenty years ago when I began writing poetry. I wrote my first breakthrough poem about an ice beast that reached its monstrous arm into the depths of the poet's body, scraping the insides of every possible meaningful emotion, leaving her empty. I was essentially communicating for the first time the violations I had repeatedly encountered. The other breakthrough, however, was that I had found a meaningful tool with which to communicate. As I worked to make the fragmented words and images on the page reflect my raw and unconscious emotional pulses, I began to see possibility through language, through revision, and through narrative. If we're wondering why so many students are interested in creative writing, one reason is that it validates their personal experiences. They are no longer being silenced.

Here is what I believe. I believe in transformation: that anyone can be an English major. I believe in possibility: that every student is capable of finding success. I believe that if we can provide our majors with support, inclusion, belonging, and purpose, we can help students succeed academically and professionally. They will become resilient and confident in their journeys to build new worlds and new futures.

\section{Notes}

1. Bill Burnett and Dave Evans approach this multiple-lives theory from a design-thinking perspective: "There is no one idea for your life. There are many lives you could live happily and productively (no matter how many years old you are), and there are lots of different paths you could take to live each of those productive, amazingly different lives" (67). Burnett and Evans focus on ideation and multiple iterations of various prototypes for life design.

2. Learning to adapt was one of the first lessons I received at my first professional job after college. I write about this experience and how this lesson can be introduced in multimodal composition classes in 
The Integrative

English Major:

Cultivating Growth,

Transformation, and

Possibility

Leeann Hunter
"Composition at Washington State University: Building a Multimodal Bricolage" (Ericsson et al.); see especially part 4, "Learning to Adapt: Students, Teachers, and Professionals in the 21st Century."

3. Read about my experiences as a child of deaf adults and how it shapes pedagogical innovations in my article "The Embodied Classroom: Deaf Gain in Multimodal Composition and Digital Studies."

4. In "Agglomeration and Job Matching among College Graduates," Jaison R. Abel and Richard Deitz report on a study that finds that $27 \%$ of college graduates secure jobs that align with their college degree and major. The likelihood of alignment increases in urban centers. Graduate degrees are not included in the study.

5. According to the report, "only $14 \%$ of graduates strongly agree that they were supported by professors who cared, made them excited about learning and encouraged their dreams" (7).

6. I piloted the program during spring 2016, collaborating with my colleagues Bryan Fry and Kristin Becker to produce seven workshops and mentor fifteen students. As of fall 2017, we have designed and delivered more than thirty workshops to over fifty students, with the assistance of more than forty faculty members and graduate students serving as workshop leaders or facilitators.

7. This workshop was inspired by an interview between Simon Sinek and the radio host Koren Motekaitis, where Sinek walks Motekaitis through various memories and stories, prompting her to share more details and provide more context. In the end, he finds a pattern in her stories. Students can sometimes be taken aback by his approach in the interview, and so I have adapted it. I use the exchange that takes place from minutes sixteen to twenty-six as a model for my own workshop.

8. Research in narrative psychology, including Julia Vassilieva's Narrative Psychology: Identity, Transformation, and Ethics, informs the process of reframing student narratives. Mary Helen ImmordinoYang's work in Emotions, Learning, and the Brain: Exploring the Educational Implications of Affective Neuroscience supports the value of connecting students' affective experiences to their educational lenses.

9. I employ Virginia Woolf's memoir, "A Sketch of the Past," to illustrate the power that memories can have over our lives and to differentiate between wide swaths of nonbeing and vivid moments of being.

10. Some of this work is inspired by the research Amy Cuddy presents in Presence: Bringing Your Boldest Self to Your Biggest Challenges.

11. Linda Flower and John Hayes consider the cognitive processes involved in writing a translation, noting, for example, that " $[\mathrm{t}]$ rying to capture the movement of a deer on ice in language is clearly a kind of translation. Even when the planning process represents one's thought in words, that representation is unlikely to be in the elaborate syntax of written English. So the writer's task is to translate a meaning" (373).

\section{Works Cited}

Abel, Jaison R., and Richard Deitz. "Agglomeration and Job Matching among College Graduates." Regional Science and Urban Economics, vol. 51, 2015, pp. 14-24. ScienceDirect, doi:10.1016/j.regsciurbeco .2014.12.001.

Burnett, Bill, and Dave Evans. Designing Your Life: How to Build a Well-Lived, Joyful Life. Knopf Doubleday, 2016.

Cuddy, Amy. Presence: Bringing Your Boldest Self to Your Biggest Challenges. Little, Brown, 2015.

Ericsson, Patricia, et al. "Composition at Washington State University: Building a Multimodal Bricolage.” Composition Forum, vol. 33, Spring 2016, compositionforum.com/issue/33/wsu.php.

Flower, Linda, and John R. Hayes. "A Cognitive Process Theory of Writing." College Composition and Communication, vol. 32, no. 4, 1981, pp. 365-87. JSTOR, www.jstor.org/stable/356600.

Great Jobs, Great Lives: The 2014 Gallup-Purdue Index Report. Gallup-Purdue, 2014.

Hunter, Leeann. "The Embodied Classroom: Deaf Gain in Multimodal Composition and Digital Studies." The Journal of Interactive Technology and Pedagogy, vol. 8, 2015, jitp.commons.gc.cuny.edu/the -embodied-classroom-deaf-gain-in-multimodal-composition-and-digital-studies/.

Immordino-Yang, Mary Helen. Emotions, Learning, and the Brain: Exploring the Educational Implications of Affective Neuroscience. W. W. Norton, 2016.

"Integrative and Applied Learning VALUE Rubric." Association of American Colleges and Universities, 2009, www.aacu.org/value/rubrics/integrative-learning.

Motekaitis, Koren. "Start with Why with Simon Sinek." How She Really Does It, 19 Dec. 2010, howshereallydoesit.com/podcast/simon-sinek/.

Sinek, Simon. Start with Why: How Great Leaders Inspire Everyone to Take Action. Penguin, 2011.

Vassilieva, Julia. Narrative Psychology: Identity, Transformation, and Ethics. Springer, 2016.

Woolf, Virginia. "A Sketch from the Past." 1940. Moments of Being, edited by Jeanne Schulkind, 2nd ed., Harvest Books, 1985. 